BMJ Open

Diabetes

Research

\& Care

\title{
Management of type 2 diabetes in chronic kidney disease
}

\author{
Jefferson L Triozzi (D , ${ }^{1}$ L Parker Gregg, ${ }^{2,3,4}$ Salim S Virani, ${ }^{5,6,7,8}$ \\ Sankar D Navaneethan (1D) 2,3,4,9
}

To cite: Triozzi JL,

Parker Gregg L, Virani SS, et al. Management of type 2 diabetes in chronic kidney disease. BMJ Open Diab Res Care 2021;9:e002300. doi:10.1136/ bmjdrc-2021-002300

Received 29 March 2021 Accepted 4 July 2021
Check for updates

(c) Author(s) (or their employer(s)) 2021. Re-use permitted under CC BY-NC. No commercial re-use. See rights and permissions. Published by BMJ.

For numbered affiliations see end of article.

Correspondence to Dr Sankar D Navaneethan; sankar.navaneethan@bcm.edu

\section{ABSTRACT}

The management of patients with type 2 diabetes and chronic kidney disease (CKD) encompasses lifestyle modifications, glycemic control with individualized $\mathrm{HbA} 1 \mathrm{C}$ targets, and cardiovascular disease risk reduction. Metformin and sodium-glucose cotransporter-2 inhibitors are first-line agents. Glucagon-like peptide-1 receptor agonists are second-line agents. The use of other antidiabetic agents should consider patient preferences, comorbidities, drug costs, and the risk of hypoglycemia. Renin-angiotensin-aldosterone system inhibitors are strongly recommended for patients with diabetes, hypertension, and albuminuria. Non-steroidal mineralocorticoid receptor antagonists, which pose less risk of hyperkalemia than steroidal agents, are undergoing further evaluation among patients with diabetic kidney disease. Here, we discuss important advancements in the management of patients with type 2 diabetes and CKD.

\section{INTRODUCTION}

Diabetic kidney disease (DKD) is the most common cause of chronic kidney disease (CKD) globally. ${ }^{1}$ DKD is characterized by albuminuria and reduced estimated glomerular filtration rate (eGFR), which are independent risk factors for end-stage kidney disease (ESKD), cardiovascular events, and death. ${ }^{23}$ However, some patients with diabetes develop reduced eGFR with minimal or no albuminuria and retain the risks of microvascular and macrovascular complications. ${ }^{4}$ Moreover, kidney biopsy data among patients with DKD indicate variability in histopathological findings and overlap with non-diabetic disease processes. ${ }^{5}$ With advancements in diabetes care and therapeutics, the prevalence of kidney disease among patients with diabetes has stabilized around $35 \%,{ }^{6}$ and the incidence of acute cardiovascular events among patients with diabetes has decreased by over $50 \% .^{7}$ Nevertheless, the absolute number of patients with diabetes is rising, with an anticipated global prevalence of $7.7 \%$ by $2030 .^{8}$ The impending burden of diabetes, in the context of the obesity epidemic, will likely affect younger patients with more time at risk to develop kidney disease and its complications. ${ }^{9}$ In this review, we describe the management of type 2 diabetes in CKD, highlight important aspects of clinical practice guidelines, and discuss the evidence that supports modern practice. ${ }^{1011}$

\section{MANAGEMENT OF TYPE 2 DIABETES IN CKD Overview}

Glycemic control delays the development of albuminuria and improves clinical outcomes in those with diabetes and kidney disease. ${ }^{12}$ DKD care requires a multifaceted approach, encompassing lifestyle modifications, glycemic control, cardiovascular risk mitigation, and blood pressure regulation with a renin-angiotensin-aldosterone system (RAAS) inhibitor. ACE inhibitors (ACEi) and angiotensin II receptor blockers reduce kidney disease progression and incident ESKD and are recommended in clinical practice guidelines. Metformin is recommended alongside sodium-glucose cotransporter-2 inhibitor (SGLT2i) as first-line DKD agents. Glucagon-like peptide-1 receptor agonists (GLP-1 RAs) are second-line agents that may decrease albuminuria and cardiovascular risk in some patients. Evolving data regarding SGLT2i, GLP-1 RA, and their combinations will likely impact standards of DKD care. Mineralocorticoid receptor antagonists (MRAs) have potential benefits in DKD, but the use of steroidal agents is limited by the risk of hyperkalemia among patients with reduced kidney function. Emerging safety and efficacy data for non-steroidal MRAs may support their adjunctive use in certain populations.

\section{Lifestyle modifications}

Lifestyle modifications encompassing dietary changes, increased physical activity, and smoking cessation have potential cardiovascular benefits and are recommended for all adults with diabetes and CKD (table 1). Studies examining the benefits of intentional weight loss in CKD are limited. However, weight loss 
Table 1 Clinical practice guidelines from KDIGO and ADA

KDIGO 2020 Clinical Practice Guideline for Diabetes Management in Chronic Kidney Disease

ADA Standards of Medical Care in Diabetes-2021

\begin{tabular}{ll}
\hline HbA1c target & $<6.5 \%$ to $<8.0 \%$ \\
\hline Blood pressure & Not included \\
\hline Sodium restriction & $<2 \mathrm{~g} /$ day \\
\hline Protein intake & $\begin{array}{l}0.8 \mathrm{~g} / \mathrm{kg} \text { body weight/day for non-dialysis-dependent } \\
\text { patients }\end{array}$
\end{tabular}

$<7 \%$ for many non-pregnant adults, less stringent $\mathrm{HbA1c}$ goals (eg, $<8 \%$ ) for patients with limited life expectancy, or where harms outweigh benefits

$<130 / 80 \mathrm{~mm} \mathrm{Hg}$ (existing ASCVD or 10-year ASCVD risk $\geq 15 \%),<140 / 90 \mathrm{~mm} \mathrm{Hg}$ (10-year ASCVD risk<15\%) $<2300 \mathrm{mg} /$ day, as part of a DASH-style eating pattern for patients with blood pressure of $>120 / 80 \mathrm{~mm} \mathrm{Hg}$

$0.8 \mathrm{~g} / \mathrm{kg}$ body weight/day for non-dialysis-dependent patients; consider higher levels of dietary protein intakes for dialysis-dependent patients

Physical activity

Moderate-intensity physical activity for $>150 \mathrm{~min} /$ week or to a level compatible with their cardiovascular and physical tolerance

$\geq 150$ min of moderate-intensity to vigorous-intensity aerobic activity per week, spread over at least 3 days/ week, with no more than 2 consecutive days without activity

Weight loss

Not included

$\geq 5 \%$ weight loss for most patients with type 2 diabetes who are overweight or obese and are ready to achieve weight loss

Tobacco

ACE inhibitor/ARB

\section{Cessation of tobacco products}

ACE inhibitor or ARB for patients with diabetes, hypertension, and albuminuria, titrated to the highest approved dose that is tolerated

\section{Metformin \\ Metformin for patients with DKD and eGFR of $>30 \mathrm{~mL} /$ $\mathrm{min} / 1.73 \mathrm{~m}^{2}$ \\ SGLT2i \\ SGLT2i for patients with DKD and eGFR of $30 \mathrm{~mL} /$ $\mathrm{min} / 1.73 \mathrm{~m}^{2}$}

$\begin{array}{ll}\text { GLP-1 RA } & \begin{array}{l}\text { GLP-1 RA for patients with DKD who have not } \\ \text { achieved individualized glycemic targets despite use } \\ \text { of metformin and SGLT2i or who are unable to use } \\ \text { those medications }\end{array} \\ \text { MRA } & \text { Not included }\end{array}$

\section{Cessation of tobacco products}

ACE inhibitor or ARB recommended for patients with diabetes and hypertension, modestly elevated UACR (30-299 $\mathrm{mg} / \mathrm{g}$ creatinine), and strongly recommended for those with UACR of $\geq 300 \mathrm{mg} / \mathrm{g}$ and/or eGFR of $<60 \mathrm{~mL} / \mathrm{min} / 1.73 \mathrm{~m}^{2}$

Metformin is the preferred initial pharmacological agent for the treatment of type 2 diabetes; metformin should be continued as long as it is tolerated and not contraindicated; other agents, including insulin, should be added to metformin.

SGLT2i for patients with DKD with eGFR of $\geq 30 \mathrm{~mL} /$ $\mathrm{min} / 1.73 \mathrm{~m}^{2}$ and UACR of $>300 \mathrm{mg} / \mathrm{g}$; SGLT2i additionally for cardiovascular risk reduction with eGFR of $\geq 30 \mathrm{~mL} / \mathrm{min} / 1.73 \mathrm{~m}^{2}$ or UACR of $>300 \mathrm{mg} / \mathrm{g}$

GLP-1 RA for patients with CKD who are at increased risk of cardiovascular events to reduce renal endpoints, primarily albuminuria, progression of albuminuria, and cardiovascular events

Not included

ADA, American Diabetes Association; ARB, angiotensin receptor blocker; ASCVD, atherosclerotic cardiovascular disease; CKD, chronic kidney disease; DASH, Dietary Approaches to Stop Hypertension; DKD, diabetic kidney disease; eGFR, estimated glomerular filtration rate; GLP-1 RA, glucagon-like peptide-1 receptor agonist; HbA1c, glycated hemoglobin; KDIGO, Kidney Disease: Improving Global Outcomes; MRA, mineralocorticoid receptor agonist; SGLT2i, sodium-glucose cotransporter-2 inhibitor; UACR, urine albumin-to-creatinine ratio.

through caloric restriction and exercise modifies cardiovascular risk factors and improves glycemic control in those with diabetes and hence likely benefits those with DKD. Restricting sodium intake to $<2 \mathrm{~g} /$ day may decrease albuminuria and maximize the effects of RAAS inhibition. Sodium-sensitive hypertension is common in DKD, and thus sodium restriction may also mediate blood pressure and reduce cardiovascular events. ${ }^{13}$ Experimental studies and clinical trials previously suggested that protein restriction reduces glomerular hyperfiltration and delays the progression of non-diabetic CKD, but there is a paucity of data in those with DKD. ${ }^{14}$ Advanced DKD is a catabolic state associated with low muscle mass, cachexia, and malnutrition, and thus very low-protein diets are potentially harmful. Protein intake of $0.8 \mathrm{~g} /$ $\mathrm{kg}$ body weight/day is recommended for non-dialysisdependent patients, and protein intake of $>1.0-1.2 \mathrm{~g} / \mathrm{kg}$ body weight/day is recommended for the hemodialysis and peritoneal dialysis population. ${ }^{1011}$

\section{Glycemic control \\ Assessment of glycemic control}

Glycated hemoglobin (HbA1c) is the preferred laboratory measure of glycemia in $\mathrm{DKD}$, with certain limitations. Changes in red blood cell turnover in advanced DKD may decrease the validity of HbA1c. ${ }^{15} \mathrm{HbAlc}$ reflects average blood glucose over 90 days and cannot adequately capture glycemic variability, which is associated with vascular complications, oxidative stress, and hypoglycemia. ${ }^{16}$ In these situations, continuous blood glucose monitoring using retrospective, real-time, or intermittent techniques provides a more accurate assessment of glycemic control. Other biomarkers, such as glycated albumin and fructosamine, have not demonstrated clear or consistent 
advantages over HbA1c in CKD. Both albumin-based assessments and fructosamine may be affected by hypoalbuminemia, a common finding among patients with advanced kidney disease. ${ }^{17}$ For most patients with DKD, HbAlc monitoring every 3-6 months is adequate to guide therapy.

\section{Glycemic target}

Individualized HbAlc targets balance the benefits (eg, reducing microvascular complications) and risks (eg, hypoglycemia) of glycemic control in those with CKD. Glycemic control decreases the incidence of kidney disease and other microvascular complications among patients with diabetes. ${ }^{18}$ This benefit is supported by clinical trial data using albuminuria and eGFR as outcome measures of DKD. The Diabetes Control and Complications Trial and the corresponding observational follow-up study, Epidemiology of Diabetes Interventions and Complications, enrolled patients with type 1 diabetes and reported a significant and durable reduction in microalbuminuria and albuminuria in the intensive glycemic control group, along with a reduction in the development of stage 3 CKD. ${ }^{19}$ The United Kingdom Prospective Diabetes Study (UKPDS) enrolled patients with type 2 diabetes and demonstrated a $33 \%$ risk reduction of incident microalbuminuria in the intensive glycemic control group. ${ }^{20}$ Other studies show that intensive glycemic control is associated with a lower risk of incident ESKD. Post-trial analysis by the Action in Diabetes and Vascular Disease: PreterAx and DiamicroN MR Controlled Evaluation study group reported a $65 \%$ reduction of ESKD in the intensive glycemic control group. ${ }^{21}$ A post hoc analysis of the Steno-2 study suggested that intensive glycemic control, as part of a multifactorial behavioral and pharmacological intervention, slows eGFR decline and reduces ESKD and death. ${ }^{22}$ However, aggressive glycemic control is associated with increased mortality in CKD. In a secondary analysis of the Action to Control Cardiovascular Risk in Diabetes trial, intensive blood glucose control in patients with CKD increased mortality. ${ }^{23}$ Hypoglycemia is the most important limiting factor for intensive glycemic control, as insulin clearance and gluconeogenesis are impaired in patients with reduced kidney function. Intensive glycemic control poses greater risks for patients receiving medications that cause hypoglycemia, such as insulin or insulin secretagogues. Other factors that support a less aggressive approach to glycemic control in CKD include shorter life expectancy, pre-existing macrovascular complications, greater comorbid conditions, hypoglycemic unawareness, and limited resources for self-care.

Clinical practice guidelines emphasize individualized HbAlc targets (table 1). The Kidney Disease: Improving Global Outcomes Diabetes Work Group recommends a target HbA1c range from $<6.5 \%$ to $<8 \%$ in non-dialysisdependent DKD. The American Diabetes Association does not make a specific HbAlc recommendation for patients with kidney disease but recommends a target of $<7 \%$ for most patients and $<8 \%$ for patients with a limited life expectancy or high risk of complications. For example, an intensive HbAlc target would benefit a younger patient with early-stage CKD and no cardiovascular complications. Whereas an intensive HbA1c target would pose greater risk than benefit for an elderly patient with advanced-stage CKD, cardiovascular complications, and risk of hypoglycemia.

\section{Pharmacological agents}

\section{Metformin}

Metformin is a first-line antidiabetic agent that can be safely administered in most patients with baseline eGFR of $>30 \mathrm{~mL} / \mathrm{min} / 1.73 \mathrm{~m}^{2}$. Metformin is a biguanide medication with multiple mechanisms of action, including insulin sensitization in peripheral tissues and the reduction of hepatic gluconeogenesis. In the UKPDS study, patients treated with metformin demonstrated decreased diabetes-related, cardiovascularrelated, and all-cause mortality when compared with insulin and sulfonylureas. ${ }^{24}$ Metformin is associated with a reduction in ESKD and adverse cardiovascular outcomes among patients with DKD when compared with other antihyperglycemic agents. ${ }^{25}$ Kwon et al reported lower all-cause mortality and ESKD progression in patients with eGFR OF $>30 \mathrm{~mL} / \mathrm{min} / 1.73 \mathrm{~m}^{2}$ prescribed metformin, with no increased incidence in all-cause lactic acidosis events. ${ }^{26}$ In separate studies, metformin was associated with decreased risk of cardiovascular events and heart failure readmissions among patients with DKD. 2728

Metformin is often underprescribed or prematurely discontinued among patients with reduced eGFR due to a perceived risk of lactic acidosis. Early biguanide medications were recalled due to life-threatening risks of lactic acidosis, but clinically significant lactic acidosis due to metformin is rare and often attributable to other acute illnesses (table 2). In a large retrospective cohort using national-level data, Lazarus et al reported no difference between hospitalization for lactic acidosis among patients with reduced kidney function taking metformin versus sulfonylureas. ${ }^{29}$ An analogous study using data from the Veteran's Health Administration found no difference in lactic acidosis hospitalizations between metformin and sulfonylurea users who developed reduced kidney function. ${ }^{30}$ In a cohort study using national-level data from Sweden, metformin demonstrated less risk of a composite endpoint of acidosis, serious infection, and all-cause mortality compared with insulin and other oral antihyperglycemic agents in the subgroup of patients with eGFR of $45-60 \mathrm{~mL} / \mathrm{min} / 1.73 \mathrm{~m}^{2}{ }^{31}$ It is recommended to continue metformin in those with eGFR of $\geq 45 \mathrm{~mL} / \mathrm{min} / 1.73 \mathrm{~m}^{2}$, titrate cautiously or halve the dose with eGFR of $30-44 \mathrm{~mL} / \mathrm{min} / 1.73 \mathrm{~m}^{2}$, and to discontinue with eGFR of $<30 \mathrm{~mL} / \mathrm{min} / 1.73 \mathrm{~m}^{2}$ and the dialysis population. Holding metformin during acute illness or acute kidney injury is reasonable. 


\begin{tabular}{|c|c|c|c|c|c|c|}
\hline Author & $\begin{array}{l}\text { Year of } \\
\text { publication }\end{array}$ & Country & $\mathbf{N}$ & Age & $\begin{array}{l}\text { HR }(95 \% \mathrm{Cl}) \text { of acidosis } \\
\text { outcome }\end{array}$ & Key findings \\
\hline Ekström et al ${ }^{31}$ & 2012 & $\begin{array}{l}\text { Swedish National Diabetes } \\
\text { Register (Sweden) }\end{array}$ & 51675 & $\begin{array}{l}\text { Mean } 65.3 \\
\text { years }\end{array}$ & $\begin{array}{l}0.85(0.74 \text { to } 0.97) \text { (eGFR } \\
\left.45-60 \mathrm{~mL} / \mathrm{min} / 1.73 \mathrm{~m}^{2}\right) ; \\
0.98(0.79 \text { to } 1.21)(\mathrm{eGFR} \\
\left.30-45 \mathrm{~mL} / \mathrm{min} / 1.73 \mathrm{~m}^{2}\right)\end{array}$ & $\begin{array}{l}\text { Compared with other oral } \\
\text { antihyperglycemic agents and insulin, } \\
\text { metformin use was associated with } \\
\text { reduced risk of acidosis and serious } \\
\text { infection and all-cause mortality in } \\
\text { patients with eGFR of } 45-60 \mathrm{~mL} / \\
\text { min } 1.73 \mathrm{~m}^{2} \text {. Metformin use was not } \\
\text { associated with increased risk of acidosis } \\
\text { and serious infection and all-cause } \\
\text { mortality in patients with eGFR of } 30- \\
45 \mathrm{~mL} / \mathrm{min} / 1.73 \mathrm{~m}^{2} \text {. }\end{array}$ \\
\hline Lazarus et a $\left.\right|^{29}$ & 2018 & $\begin{array}{l}\text { Geisinger Health System } \\
\text { (USA) }\end{array}$ & 75413 & $\begin{array}{l}\text { Mean } 60.4 \\
\text { years }\end{array}$ & $\begin{array}{l}1.16(0.95 \text { to } 1.41)(\mathrm{eGFR} \\
\left.45-59 \mathrm{~mL} / \mathrm{min} / 1.73 \mathrm{~m}^{2}\right) ; \\
1.09(0.83 \text { to } 1.44)(\mathrm{eGFR} \\
\left.30-44 \mathrm{~mL} / \mathrm{min} / 1.73 \mathrm{~m}^{2}\right) ; \\
2.07(1.33 \text { to } 3.22)(\mathrm{eGFR} \\
\left.<30 \mathrm{~mL} / \mathrm{min} / 1.73 \mathrm{~m}^{2}\right)\end{array}$ & $\begin{array}{l}\text { Metformin use was not associated with } \\
\text { incident acidosis among patients with } \\
\text { eGFR of }>30 \mathrm{~mL} / \mathrm{min} / 1.73 \mathrm{~m}^{2} \text {. Metformin } \\
\text { use was associated with increased } \\
\text { incident acidosis among patients with } \\
\text { eGFR of }<30 \mathrm{~mL} / \mathrm{min} / 1.73 \mathrm{~m}^{2} \text {. }\end{array}$ \\
\hline Chu et $a l^{30}$ & 2020 & $\begin{array}{l}\text { National Veterans Health } \\
\text { Administration, Medicare, } \\
\text { Medicaid, National Death } \\
\text { Index (USA) }\end{array}$ & 49204 & $\begin{array}{l}\text { Median } 70 \\
\text { years }\end{array}$ & $\begin{array}{l}1.21(0.99 \text { to } 1.50)(e G F R \\
\left.<60 \mathrm{~mL} / \mathrm{min} / 1.73 \mathrm{~m}^{2}\right)\end{array}$ & $\begin{array}{l}\text { Among patients who developed reduced } \\
\text { kidney function, the rate of lactic acidosis } \\
\text { hospitalization was not statistically } \\
\text { different between metformin users and } \\
\text { sulfonylurea users. }\end{array}$ \\
\hline
\end{tabular}

eGFR, estimated glomerular filtration rate.

\section{Sodium-glucose cotransporter-2 inhibitor}

SGLT2i blocks the reabsorption of glucose and sodium in the proximal convoluted tubule, producing natriuresis and glucosuria. There is substantial evidence to support a reduced risk of ESKD, cardiovascular death, and hospitalization for heart failure. The cardiovascular and kidney benefits of SGLT2i are independent of the antihyperglycemic effect, which attenuates with lower eGFR. SGLT2i may improve glomerular hemodynamics, reduce oxidative stress, and optimize tissue energetics. ${ }^{32}$

\section{SGLT2i efficacy for kidney and cardiovascular outcomes}

Large cardiovascular safety trials of SGLT2i demonstrated favorable secondary kidney outcomes among patients with type 2 diabetes and variable baseline kidney function (table 3). Empagliflozin, Cardiovascular Outcomes, and Mortality in Type 2 Diabetes (EMPA-REG OUTCOME) enrolled patients with eGFR of $\geq 30 \mathrm{~mL} / \mathrm{min} / 1.73 \mathrm{~m}^{2}$ and demonstrated a $46 \%$ risk reduction of the composite secondary kidney outcome of doubling of serum creatinine, initiation of kidney replacement therapy, or renal death. ${ }^{33}$ In a post hoc analysis of EMPA-REG OUTCOME, empagliflozin demonstrated improved kidney function regardless of the baseline eGFR or degree of albuminuria. ${ }^{34}$ Canagliflozin and Cardiovascular and Renal Events in Type 2 Diabetes (CANVAS) enrolled patients with eGFR of $\geq 30 \mathrm{~mL} / \mathrm{min} / 1.73 \mathrm{~m}^{2}$ and reported a $40 \%$ reduction in the composite secondary kidney outcome. ${ }^{35}$ Dapagliflozin and Cardiovascular Outcomes in Type 2 Diabetes (DECLARE-TIMI 58) enrolled patients with eGFR of $\geq 60 \mathrm{~mL} / \mathrm{min} / 1.73 \mathrm{~m}^{2}$ and reported a $47 \%$ risk reduction in the composite secondary kidney outcome. ${ }^{36}$ However, in the Cardiovascular Outcomes with Ertugliflozin in Type 2 Diabetes (VERTIS CV) study, the reduction in the secondary composite kidney outcome was not statistically significant. EMPA-REG OUTCOME and CANVAS both demonstrated a significant reduction in the primary cardiovascular safety outcome, and DECLARE-TIMI 58 and VERTIS CV reached cardiovascular non-inferiority. These data argued for dedicated SGLT2i trials in the DKD population.

The Canagliflozin and Renal Outcomes in Type 2 Diabetes and Nephropathy (CREDENCE) trial was a seminal study of SGLT2i in DKD with a dedicated primary composite kidney outcome. ${ }^{37}$ CREDENCE enrolled patients with type 2 diabetes, eGFR of $30-90 \mathrm{~mL} /$ $\min / 1.73 \mathrm{~m}^{2}$, and a urine albumin-to-creatinine ratio of $300-5000 \mathrm{mg} / \mathrm{g}$. The prespecified enrollment strategy aimed to include at least $60 \%$ of patients with eGFR of $<60 \mathrm{~mL} / \mathrm{min} / 1.73 \mathrm{~m}^{2}$, a population at higher risk of ESKD than previously studied. In this double-blind, placebo-controlled trial, canagliflozin reduced the primary composite kidney endpoint by $31 \%$, with a noteworthy benefit in a secondary heart failure outcome. The trial was prematurely discontinued after 2.6 years due to overwhelming efficacy. CREDENCE demonstrated kidney benefits independent of baseline HbAlc, extent of $\mathrm{HbAlc}$ reduction, and stage of $\mathrm{CKD}$, leading to the first kidney-related indication for SGLT2i by the US FDA in 2019.

There is evolving information about the use of SGLT2i among patients with eGFR of $<30 \mathrm{~mL} / \mathrm{min} / 1.73 \mathrm{~m}^{2}$ and non-DKD. Dapagliflozin in Patients with Chronic Kidney Disease included 4304 participants, two-thirds with diabetes, with eGFR of $25-75 \mathrm{~mL} / \mathrm{min} / 1.73 \mathrm{~m}^{2}$. Dapagliflozin reduced the composite risk of $\geq 50 \%$ eGFR decline, ESKD, and renal or cardiovascular death by 
Table 3 Selected clinical trials of SGLT2i and SGLT1/2i, empagliflozin, canagliflozin, dapagliflozin, ertugliflozin, and sotagliflozin

\begin{tabular}{|c|c|c|c|c|c|c|c|}
\hline $\begin{array}{l}\text { SGLT2i or } \\
\text { SGLT1/2i }\end{array}$ & Trial & Intervention & $\mathbf{N}$ & $\begin{array}{l}\text { Mean baseline } \\
\text { eGFR }(\mathrm{mL} / \\
\left.\mathrm{min} / 1.73 \mathrm{~m}^{2}\right)\end{array}$ & $\begin{array}{l}\text { Median } \\
\text { follow-up } \\
\text { (years) }\end{array}$ & $\begin{array}{l}\text { Primary composite } \\
\text { outcome (HR }(95 \% \mathrm{Cl}) \text { ) }\end{array}$ & $\begin{array}{l}\text { Kidney outcome (HR } \\
(95 \% \mathrm{CI}))\end{array}$ \\
\hline Empagliflozin & $\begin{array}{l}\text { EMPA-REG } \\
\text { OUTCOME }\end{array}$ & $\begin{array}{l}\text { Empagliflozin } 10 \mathrm{mg} \\
\text { once per day, } \\
\text { empagliflozin } 25 \mathrm{mg} \\
\text { once per day, or placebo }\end{array}$ & 7020 & 74 & 3.1 & $\begin{array}{l}\text { Death from cardiovascular } \\
\text { causes, non-fatal myocardial } \\
\text { infarction (excluding silent } \\
\text { myocardial infarction), or } \\
\text { non-fatal stroke }(0.86(0.74 \\
\text { to } 0.99))\end{array}$ & $\begin{array}{l}\text { Doubling of serum } \\
\text { creatinine with eGFR of } \\
\leq 45 \mathrm{~mL} / \mathrm{min} / 1.73 \mathrm{~m}^{2} \text {, renal } \\
\text { replacement therapy, or } \\
\text { renal death }(0.54(0.40 \text { to } \\
0.75))\end{array}$ \\
\hline \multirow[t]{2}{*}{ Canagliflozin } & CANVAS & $\begin{array}{l}\text { Canagliflozin } 100 \mathrm{mg} \\
\text { once per day, with an } \\
\text { optional increase to } \\
300 \mathrm{mg} \text { once per day, or } \\
\text { placebo }\end{array}$ & 10142 & 76.5 & 2.4 & $\begin{array}{l}\text { Death from cardiovascular } \\
\text { causes, non-fatal myocardial } \\
\text { infarction, or non-fatal stroke } \\
(0.86(0.75 \text { to } 0.97))\end{array}$ & $\begin{array}{l}\geq 40 \% \text { reduction in eGFR, } \\
\text { renal replacement therapy } \\
\text { (transplant, chronic } \\
\text { dialysis, or sustained } \\
\left.\text { eGFR }<15 \mathrm{~mL} / \mathrm{min} / 1.73 \mathrm{~m}^{2}\right) \text {, } \\
\text { or renal death }(0.53(0.33 \\
\text { to } 0.84) \text { ) }\end{array}$ \\
\hline & CREDENCE & $\begin{array}{l}\text { Canagliflozin } 100 \mathrm{mg} \\
\text { once per day or placebo }\end{array}$ & 4401 & 56.2 & 2.62 & $\begin{array}{l}\text { ESKD (dialysis, } \\
\text { transplantation, or a } \\
\text { sustained eGFR of }<15 \mathrm{~mL} / \\
\left.\text { min } / 1.73 \mathrm{~m}^{2}\right) \text {, a doubling } \\
\text { of the serum creatinine } \\
\text { level, or death from renal or } \\
\text { cardiovascular causes }(0.70 \\
(0.59 \text { to } 0.82))\end{array}$ & $\begin{array}{l}\text { See primary composite } \\
\text { outcome. }\end{array}$ \\
\hline \multirow[t]{2}{*}{ Dapagliflozin } & $\begin{array}{l}\text { DECLARE- } \\
\text { TIMI } 58\end{array}$ & $\begin{array}{l}\text { Dapagliflozin } 10 \mathrm{mg} \text { once } \\
\text { per day or placebo }\end{array}$ & 17160 & 85.1 & 4.2 & $\begin{array}{l}\text { Cardiovascular death, } \\
\text { myocardial infarction, or } \\
\text { ischemic stroke }(0.93(0.84 \\
\text { to } 1.03))\end{array}$ & $\begin{array}{l}\geq 40 \% \text { reduction in eGFR } \\
\text { to }<60 \mathrm{~mL} / \mathrm{min} / 1.73 \mathrm{~m}^{2}, \\
\text { ESKD (dialysis } \geq 90 \text { days, } \\
\text { transplant or sustained } \\
\left.\text { eGFR } 15 \mathrm{~mL} / \mathrm{min} / 1.73 \mathrm{~m}^{2}\right) \text {, } \\
\text { or renal or cardiovascular } \\
\text { death }(0.53(0.43 \text { to } 0.66))\end{array}$ \\
\hline & DAPA-CKD & $\begin{array}{l}\text { Dapagliflozin } 10 \mathrm{mg} \text { once } \\
\text { per day or placebo }\end{array}$ & 4304 & 43.1 & 2.4 & $\begin{array}{l}\text { Sustained decline in the } \\
\text { eGFR of at least } 50 \% \text {, } \\
\text { ESKD, or death from renal or } \\
\text { cardiovascular causes }(0.61 \\
(0.51 \text { to } 0.72))\end{array}$ & $\begin{array}{l}\text { See primary composite } \\
\text { outcome. }\end{array}$ \\
\hline Ertugliflozin & VERTIS CV & $\begin{array}{l}\text { Ertugliflozin } 5 \mathrm{mg} \text { once } \\
\text { per day, ertugliflozin } \\
15 \mathrm{mg} \text { once per day, or } \\
\text { placebo }\end{array}$ & 8246 & 76.1 & 3.0 & $\begin{array}{l}\text { Death from cardiovascular } \\
\text { causes, non-fatal myocardial } \\
\text { infarction, or non-fatal stroke } \\
(0.97(0.85 \text { to } 1.11))\end{array}$ & $\begin{array}{l}\text { Death from renal causes, } \\
\text { renal replacement therapy, } \\
\text { or doubling of the serum } \\
\text { creatinine level }(0.81 \text { ( } 0.63 \\
\text { to } 1.04))\end{array}$ \\
\hline Sotagliflozin & SCORED & $\begin{array}{l}\text { Sotagliflozin } 200 \mathrm{mg} \\
\text { once per day, with an } \\
\text { optional increase to } \\
400 \mathrm{mg} \text { once per day, or } \\
\text { placebo }\end{array}$ & 10584 & 44.4 & 1.3 & $\begin{array}{l}\text { Total number of deaths } \\
\text { from cardiovascular causes, } \\
\text { hospitalizations for heart } \\
\text { failure, and urgent visits for } \\
\text { heart failure }(0.74 \text { ( } 0.63 \text { to } \\
0.88))\end{array}$ & $\begin{array}{l}\text { Sustained decrease } \\
\text { of } \geq 50 \% \text { in the eGFR } \\
\text { from baseline for } \geq 30 \\
\text { days, long-term dialysis, } \\
\text { renal transplantation, or } \\
\text { sustained eGFR of }<15 \mathrm{~mL} \\
\text { min } 1.73 \mathrm{~m}^{2} \text { for } \geq 30 \text { days } \\
(0.71(0.46 \text { to } 1.08))\end{array}$ \\
\hline
\end{tabular}

CANVAS, Canagliflozin and Cardiovascular and Renal Events in Type 2 Diabetes; CREDENCE, Canagliflozin and Renal Outcomes in Type 2 Diabetes and Nephropathy; DAPA-CKD, Dapagliflozin in Patients with Chronic Kidney Disease; DECLARE-TIMI 58, Dapagliflozin and Cardiovascular Outcomes in Type 2 Diabetes; eGFR, estimated glomerular filtration rate; EMPA-REG OUTCOME, Empagliflozin, Cardiovascular Outcomes, and Mortality in Type 2 Diabetes; ESKD, end-stage kidney disease; SCORED, Sotagliflozin in Patients with Diabetes and Chronic Kidney Disease; SGLT2i, sodium-glucose cotransporter-2 inhibitors; SGLT1/2i, combined sodium-glucose cotransporter-1 and -2 inhibitors; VERTIS CV, Cardiovascular Outcomes with Ertugliflozin in Type 2 Diabetes.

$39 \%$. In subgroup analyses, the benefit of dapagliflozin was consistent regardless of $\mathrm{HbA1c}$, eGFR, or presence of diabetes. The Study of Heart and Kidney Protection With Empagliflozin (EMPA-KIDNEY) is an ongoing study that will report the effect of empagliflozin on kidney progression or cardiovascular $(\mathrm{CV})$ death. ${ }^{38}$ EMPA-KIDNEY will deliver important information among patients with or without diabetes, with or without albuminuria, and eGFR as low as $20 \mathrm{~mL} / \mathrm{min} / 1.73 \mathrm{~m}^{2}$.

\section{Dual SGLT1 and SGLT2 inhibition}

Sotagliflozin is a dual SGLT1 and SGLT2 inhibitor with antihyperglycemic efficacy in both type 1 and type 2 diabetes. ${ }^{39}$ The SGLT1 cotransporter is also present in the gastrointestinal lumen, where it delays glucose absorption and reduces postprandial blood glucose levels. ${ }^{40} \mathrm{In}$ the Sotagliflozin in Patients with Diabetes and Chronic Kidney Disease (SCORED) trial, sotagliflozin decreased a composite outcome of cardiovascular death, hospitalization for heart failure, and urgent heart failure among patients with DKD with or without albuminuria. ${ }^{41}$ Sotagliflozin in Patients with Diabetes and Recent Worsening Heart Failure (SOLOIST-WHF) enrolled patients with diabetes during acute heart failure hospitalization and demonstrated improved heart failure outcomes among a 
population with mean eGFR $50 \mathrm{~mL} / \mathrm{min} / 1.73 \mathrm{~m}^{2} .{ }^{42}$ Both SCORED and SOLOIST-WHF reported several adverse events and prominent gastrointestinal upset with sotagliflozin, which may hinder its widespread use.

\section{SGLT2i safety}

SGLT2i safety data are extrapolated from trials that were not powered to detect individual adverse events. In a large meta-analysis, SGLT2i was associated with increased genital mycotic infections but not bacterial urinary tract infections. ${ }^{43}$ Genital mycotic infections are more common in women and manageable with antifungal therapy. Studies suggesting risks of Fournier's gangrene are limited by low event rates. ${ }^{44}$ SGLT2i decreases available carbohydrate and drives metabolism towards more efficient ketone-based energy sources, leading to weight loss, decreased tissue adiposity, and increased serum concentrations of $\beta$-hydroxybutyrate. ${ }^{45}$ Diabetic ketoacidosis, including euglycemic ketoacidosis, is more likely to develop among patients with certain risk factors, such as insulin dependence or acute stress states. ${ }^{46}$ A cohort study in the USA identified a twofold increase in ketoacidosis among new users of SGLT2i compared with dipeptidyl peptidase-4 inhibitors (DPP4i). ${ }^{47}$ Amputation, fracture, and acute kidney injury have also been reported. A risk of leg and foot amputation reported in CANVAS (amputation event rate of 6.3 per 1000 patient-years, $p<0.001$ ) was ultimately not observed in CREDENCE. ${ }^{35}$ The US FDA subsequently recalled a black box amputation warning for canagliflozin. Similarly, a risk of fracture reported in CANVAS (15.4 fracture events per 1000 patient-years, $\mathrm{p}<0.001)$ was not observed in other SGLT2i trials. ${ }^{33} 3536$ Finally, pooled analyses suggest SGLT2i is indeed associated with decreased risk of acute kidney injury. ${ }^{48}$ Volume depletion was proposed as a mechanism for amputation, fracture, and acute kidney injury, although the relative increase in urinary volume related to SGLT2i is transient. ${ }^{49}$

Clinical practice guidelines now recommend SGLT2i for patients with type 2 diabetes with DKD and eGFR of $\geq 30 \mathrm{~mL} / \mathrm{min} / 1.73 \mathrm{~m}^{2}$. It is reasonable to temporarily hold SGLT2i when predisposed to volume depletion or ketoacidosis, such as surgery, fasting states, or acute illnesses. History of urinary tract infection is not a contraindication to SGLT2i. In the absence of clear risk factors, the potential cardiovascular and kidney benefits justify SGLT2i therapy for most patients with DKD.

\section{Glucagon-like peptide-1 receptor agonist}

Incretin-based therapies stimulate postprandial neuroendocrine pathways to increase pancreatic insulin secretion, suppress glucagon release, increase satiety, and delay gastric emptying. In addition to an antihyperglycemic effect, incretin-based therapies improve risk factors for cardiovascular and kidney disease by improving blood pressure, body weight, and lipid profile. Other antiinflammatory properties are proposed. ${ }^{50}$ Whereas DPP4i transiently reduces the breakdown of physiological incretin hormones, GLP-1 RA with prolonged half-lives resists degradation by DPP4 and stimulate incretin receptors at supraphysiological levels. As a possible consequence, GLP-1 RA has a greater effect in DKD.

\section{Evidence for GLP-1 RA in DKD}

We lack dedicated DKD clinical trials of GLP-1 RA with predefined primary kidney endpoints. Nonetheless, some GLP-1 RA have demonstrated improved secondary microvascular outcomes in cardiovascular safety trials, driven by a reduction of albuminuria (table 4). Of the available GLP-1 RA, liraglutide, semaglutide, and dulaglutide have demonstrated both cardiovascular benefits and antialbuminuric effects. Exenatide and lixisenatide have demonstrated cardiovascular safety without a cardiovascular benefit. All therapies are administered as subcutaneous injection except for an oral formulation of semaglutide, which has demonstrated cardiovascular safety without a cardiovascular benefit.

Liraglutide and Cardiovascular Outcomes in Type 2 Diabetes (LEADER) was a placebo-controlled cardiovascular safety trial of liraglutide and included a secondary composite microvascular outcome. The reduction in the microvascular outcome, solely driven by reduced incidence of albuminuria, was independent of baseline HbA1c. ${ }^{51}$ Similarly, Semaglutide and Cardiovascular Outcomes in Patients with Type 2 Diabetes (SUSTAIN-6) demonstrated both cardiovascular safety and a decreased secondary microvascular outcome driven by reduced incidence of microalbuminuria. SUSTAIN-6 had a surprising increase in retinopathy events not previously reported in incretin trials. ${ }^{52}$ An oral formulation of semaglutide was subsequently studied in the Oral Semaglutide and Cardiovascular Outcomes in Patients with Type 2 Diabetes (PIONEER-6) trial. Oral semaglutide demonstrated cardiovascular safety without cardiovascular superiority, with no significant difference eGFR change from baseline. ${ }^{53}$ In LEADER, greater cardiovascular benefit was seen among patients with eGFR $<60 \mathrm{~mL} / \mathrm{min} / 1.73$ $\mathrm{m}^{2}$. In SUSTAIN-6 and PIONEER, however, there was no difference in cardiovascular safety stratified by stage of CKD.

Other than an apparent antialbuminuric effect, there is limited evidence that GLP-1 RA influences eGFR decline or other clinically meaningful kidney outcomes. In a prespecified kidney analysis of LEADER, there was a statistically less eGFR decline among patients receiving liraglutide versus placebo, only present in the eGFR of $30-60 \mathrm{~mL} / \mathrm{min} / 1.73 \mathrm{~m}^{2}$ subgroup. $^{51}$ In the Dulaglutide versus Insulin Glargine in Patients with Type 2 Diabetes and Moderate-to-Severe CKD (AWARD-7) study, dulaglutide demonstrated significantly less eGFR decline $\left(-1.1 \mathrm{~mL} / \mathrm{min} / 1.73 \mathrm{~m}^{2}\right)$ than daily titrated insulin glargine $\left(-2.9 \mathrm{~mL} / \mathrm{min} / 1.73 \mathrm{~m}^{2}\right)$ after a 52 -week follow-up period. ${ }^{54}$ Although dulaglutide was associated with reduced albuminuria in the placebo-controlled Dulaglutide and Cardiovascular Outcomes in Type 2 Diabetes trial, there were no differences in albuminuria 


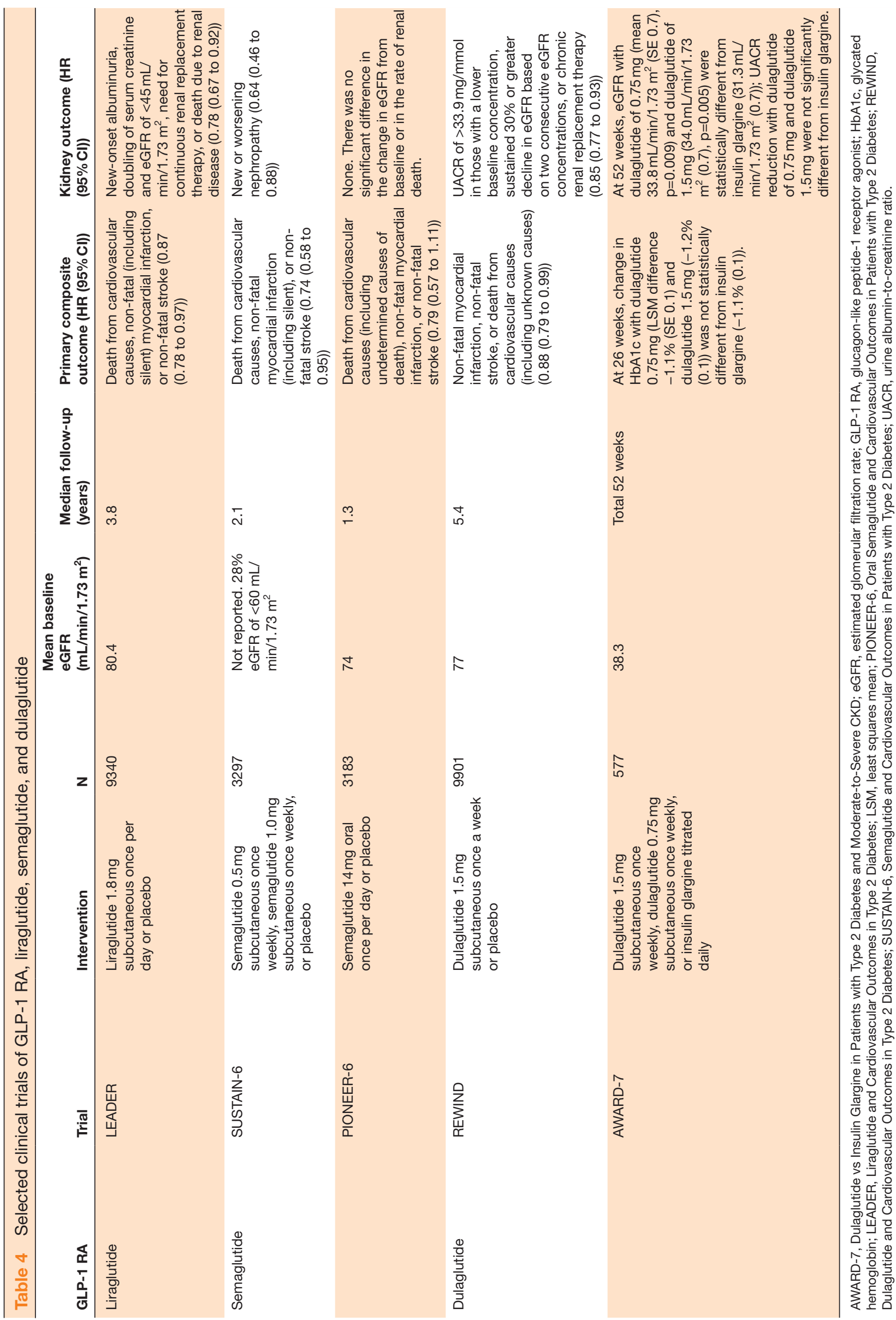


in comparison with insulin glargine in the AWARD-7 trial. ${ }^{55}$ A dedicated kidney outcomes trial for GLP-1 RA will clarify their use in DKD. A Research Study to See How Semaglutide Works Compared with Placebo in People With Type 2 Diabetes and Chronic Kidney Disease (FLOW) is a placebo-controlled, phase III trial of semaglutide with a primary kidney outcome set to complete in 2024 (NCT03819153). FLOW is enrolling adults with DKD and will report the effect of semaglutide on the primary renal composite outcome of eGFR decline, kidney failure, or death from kidney or cardiovascular disease.

\section{Combination of SGLT2i and GLP-1 RA}

SGLT2i and GLP-1 RA have distinct clinical effects. In a systematic review and trial-level meta-analysis, GLP-1 RA and SGLT2i reduced cardiovascular events to a similar degree among patients with established atherosclerotic cardiovascular disease, but SGLT2i had a greater impact on preventing heart failure hospitalizations and DKD progression. ${ }^{56}$ Further supported by dedicated heart failure studies, SGLT2i is now incorporated into guidelinedirected strategies for congestive heart failure. ${ }^{57}$ GLP-1 RA has not demonstrated benefit in heart failure. GLP-1 RA have a class interaction with the sympathetic nervous system, reflected by increased heart rate, with some signal towards harm in heart failure ${ }^{58}$ Combination of SGLT2i and incretin-based therapies may be synergistic, as both drug classes mitigate cardiovascular risk factors through improvements in weight, lipid profile, and blood pressure. Dapagliflozin and exenatide, studied alone and in combination, demonstrated improved glycemic control and cardiovascular risk in combination. The benefits of combined dapagliflozin and exenatide persisted through the 2-year follow-up, although no long-term kidney outcomes were reported. ${ }^{59}$

Clinical practice guidelines recommend GLP-1 RA in DKD based on potential cardiovascular risk reduction and antialbuminuric effects of certain agents. GLP-1 RA compounds with long-half-lives will require less frequent dosing and may have better compliance. Dulaglutide, exenatide, and semaglutide have extended-release formulations. Dulaglutide, liraglutide, lixisenatide, and semaglutide are not eliminated by the kidneys. The oral formulation of semaglutide is available for patients with an aversion to needles. Dedicated safety studies of GLP-1 RA have not been performed among patients with reduced kidney function. Slow titration to the maximally indicated dose is recommended to lower the risk of hypoglycemia and to mitigate gastrointestinal upset, the most reported side effect.

\section{Other antidiabetic agents}

We have discussed the roles of metformin, SGLT2i, and GLP-1 RA in detail. There are limited head-to-head efficacy data for other antidiabetic agents among patients with DKD ${ }^{60}$ Selection of other antidiabetic agents should consider patient preferences, comorbidities, drug costs, and the risk of hypoglycemia. Any antidiabetic agent with a prolonged duration of action, active metabolites, and elimination by the kidneys poses greater risk of hypoglycemia among patients with reduced kidney function. Sulfonylureas stimulate endogenous insulin secretion and are predominately eliminated by the kidneys. The sulfonylureas glipizide, glicazide, and glimepiride can be prescribed in eGFR $<60 \mathrm{~mL} / \mathrm{min} / 1.73 \mathrm{~m}^{2}$, but glyburide has active metabolites and should be avoided. Glinides exert similar effects as sulfonylureas but have a shorter onset and duration of action. Repaglinide is metabolized by both the liver and kidneys and can be prescribed in eGFR of $<60 \mathrm{~mL} / \mathrm{min} / 1.73 \mathrm{~m}^{2}$, but nateglinide has active metabolites and should be avoided. Both sulfonylureas and glinides should be avoided in eGFR of $<15 \mathrm{~mL} /$ $\mathrm{min} / 1.73 \mathrm{~m}^{2}$ and the dialysis population. Disaccharidase inhibitors, such as acarbose and miglitol, delay carbohydrate digestion in the gut. Although disaccharidase inhibitors pose less risk of hypoglycemia, they are generally not recommended in advanced CKD due to limited safety data. Thiazolidinediones increase insulin sensitivity in peripheral tissues, have less risk of hypoglycemia, and do not require dose adjustments for patients with reduced kidney function and the dialysis population. Thiazolidinediones may cause weight gain and fluid retention. Insulin may be required for patients with progressive insulin resistance and pancreatic dysfunction. Insulin is eliminated by the kidneys and has potent glucose lowering effects. Patient education, routine monitoring, and dose reductions based on the degree of kidney disease are important to reduce the risk of hypoglycemia.

\section{RAAS blockade}

RAAS inhibitors

RAAS blockade delays DKD progression in patients with albuminuria and hypertension. ${ }^{61}$ RAAS activation, mediated by the bioactive end products angiotensin II and aldosterone, causes increased sodium avidity and vascular tone, glomerular injury, and proteinuria. RAAS activation also contributes to systemic inflammation, the production of reactive oxygen species, and fibrosis in the kidney and cardiovascular systems. ACEi and angiotensin receptor blockers (ARBs) remain the mainstay RAAS inhibitors since their implementation at the turn of the century. Clinical practice guidelines recommend ACEi or ARB monotherapy titrated to the maximally titrated dose. Patients should be monitored for hyperkalemia or acute kidney injury ( $>30 \%$ elevation of serum creatinine) after initiating or increasing the dose of RAAS inhibitors.

\section{Mineralocorticoid receptor agonists}

MRAs may be an important component of RAAS blockade. MRAs reduce albuminuria and secondary markers of fibrosis and inflammation in the kidney. MRAs are also indicated for many common DKD comorbidities, including resistant hypertension and congestive heart failure. Despite these potential benefits, the use of MRAs in DKD is limited by the risk of hyperkalemia posed by 
steroidal MRAs like spironolactone and eplerenone. In a meta-analysis of 19 trials, the addition of steroidal MRAs to RAAS inhibitors resulted in a threefold risk of hyperkalemia. ${ }^{62}$ Potassium binders, low potassium diets, or diuretics were often used to mitigate the hyperkalemia risk in these trials, although unsuccessfully. Adverse safety events precluded adequate follow-up periods to detect cardiovascular and kidney endpoints in these trials.

\section{Finerenone}

Finerenone is a non-steroidal, dihydropyridine-based MRA with high affinity for the mineralocorticoid receptor, posing less risk of hyperkalemia. ${ }^{63}$ The Mineralocorticoid Receptor Antagonist Tolerability StudyDiabetic Nephropathy (ARTS-DN) study assessed varied doses of finerenone versus placebo among patients with diabetes and eGFR of $>30 \mathrm{~mL} / \mathrm{min} / 1.73 \mathrm{~m}^{2}$. ARTS-DN resulted in a dose-dependent reduction in albuminuria at 90 days with no risk of hyperkalemia. ${ }^{64}$ Efficacy and Safety of Finerenone in Subjects With Type 2 Diabetes Mellitus and Diabetic Kidney Disease (FIDELIO-DKD) demonstrated that those treated with finerenone had decreased CKD progression and cardiovascular events in $\mathrm{DKD}$, with an $18 \%$ reduction of the primary composite outcome of kidney failure, sustained decrease of eGFR by at least $40 \%$, or renal death. ${ }^{65}$ This outcome was driven by the reduction in eGFR, with no difference in the rate of kidney failure. There were more hyperkalemia events in the finerenone group (15.8\%) than placebo $(7.8 \%)$, although the study was not powered to assess adverse events. FIGARO-DKD is an ongoing study of finerenone that will examine a primary cardiovascular outcome event with secondary kidney endpoints among a similar DKD population (NCT02545049).

\section{CONCLUSION}

There has been great progress in the management of patients with type 2 diabetes and CKD. DKD management is multifaceted and individualized. A more lenient HbAlc target is appropriate in older adults and patients with advanced DKD or increased risk of hypoglycemia. Metformin is an important first-line, cost-effective agent with significant data supporting efficacy and safety for patients with DKD. SGLT2i is a first-line agent based on substantial clinical trial data supporting a reduction in ESKD, cardiovascular death, and hospitalization for heart failure. GLP-1 RA is a second-line agent that may reduce albuminuria and cardiovascular disease risk. Other antidiabetic agents, such as sulfonylureas, glinides, disaccharidase inhibitors, thiazolidinediones, and insulin, may be used for glycemic control based on the stage of kidney disease, individual risks and benefits. ACEi or ARB monotherapy is strongly recommended for patients with diabetes, hypertension, and albuminuria. Mineralocorticoid receptor antagonism is an unmet need in DKD due to the risk of hyperkalemia with steroidal MRA agents. Non-steroidal MRAs like finerenone have better safety profiles and may prove beneficial for certain patients with DKD. Effective DKD therapies target the shared pathways of diabetes, cardiovascular disease, and kidney disease, and a comprehensive approach will improve global outcomes for patients with DKD.

\section{Author affiliations}

${ }^{1}$ Department of Medicine, Baylor College of Medicine, Houston, Texas, USA ${ }^{2}$ VA Health Services Research and Development Center for Innovations in Quality, Effectiveness and Safety, Houston, Texas, USA

${ }^{3}$ Selzman Institute for Kidney Health, Section of Nephrology, Department of Medicine, Baylor College of Medicine, Houston, Texas, USA

${ }^{4}$ Section of Nephrology, Michael E. DeBakey VA Medical Center, Houston, Texas, USA

${ }^{5}$ Health Policy, Quality \& Informatics Program, Michael E. DeBakey VA Medical Center Health Services Research \& Development Center for Innovations, Houston, Texas, USA

${ }^{6}$ Section of Health Services Research, Department of Medicine, Baylor College of Medicine, Houston, Texas, USA

${ }^{7}$ Section of Cardiology, Michael E. DeBakey VA Medical Center, Houston, Texas, USA ${ }^{8}$ Section of Cardiovascular Research, Department of Medicine, Baylor College of Medicine, Houston, Texas, USA

${ }^{9}$ Institute of Clinical and Translational Research, Baylor College of Medicine, Houston, Texas, USA

Contributors JLT and SDN planned the contents of the review. JLT and SDN drafted the review and tables. LPG and SSV critically reviewed and edited the manuscript, and all authors were involved in the revision of the manuscript.

Funding SDN is supported by research funding from the Department of Veterans Affairs Health Services Research \& Development (1101HX002917-01A1) and a grant from the National Institutes of Health (NIDDK-R01DK101500). SSV is supported by a grant from the Department of Veterans Affairs Health Services Research and Development (1101HX002917-01A1), World Heart Federation, and Tahir and Jooma Family. This work was also supported in part by the Center for Innovations in Quality, Effectiveness and Safety (CIN 13-413), Michael E. DeBakey VA Medical Center, Houston, Texas. SDN, LPG, SSV are employees of the US Department of Veterans Affairs. The interpretation and reporting of these data are the responsibility of the authors and in no way should be viewed as official policy or interpretation of the Department of Veterans Affairs or the US government. Funding agencies did not have any role in study design, data collection, analysis, reporting, or the decision to submit for publication. The content is solely the responsibility of the authors and does not necessarily represent the official views of the National Institutes of Health or Veterans Administration.

Competing interests SDN reports personal fees from Bayer, BoehringerIngelheim, REATA, Tricida, and Vifor, and grants from Keryx outside the submitted work. SSV has received honorarium from the American College of Cardiology in his role as the associate editor for Innovations, ACC.org. All remaining authors have nothing to disclose.

Patient consent for publication Not required.

Provenance and peer review Commissioned; externally peer reviewed.

Data availability statement № data are available. This is not a clinical trial.

Open access This is an open access article distributed in accordance with the Creative Commons Attribution Non Commercial (CC BY-NC 4.0) license, which permits others to distribute, remix, adapt, build upon this work non-commercially, and license their derivative works on different terms, provided the original work is properly cited, appropriate credit is given, any changes made indicated, and the use is non-commercial. See: http://creativecommons.org/licenses/by-nc/4.0/.

ORCID IDs

Jefferson L Triozzi http://orcid.org/0000-0002-3607-6838

Sankar D Navaneethan http://orcid.org/0000-0002-4953-7795

\section{REFERENCES}

1 Bikbov B, Purcell CA, Levey AS, et al. Global, regional, and national burden of chronic kidney disease, 1990-2017: a systematic analysis for the global burden of disease study 2017. The Lancet 2020;395:709-33. 
2 Ninomiya T, Perkovic V, de Galan BE, et al. Albuminuria and kidney function independently predict cardiovascular and renal outcomes in diabetes. JASN 2009;20:1813-21.

3 Berhane AM, Weil EJ, Knowler WC, et al. Albuminuria and estimated glomerular filtration rate as predictors of diabetic end-stage renal disease and death. Clin J Am Soc Nephrol 2011;6:2444-51.

4 Porrini E, Ruggenenti P, Mogensen CE, et al. Non-proteinuric pathways in loss of renal function in patients with type 2 diabetes. Lancet Diabetes Endocrinol 2015;3:382-91.

5 Fiorentino M, Bolignano D, Tesar V, et al. Renal biopsy in patients with diabetes: a pooled meta-analysis of 48 studies. Nephrol Dial Transplant 2017;32:97-110.

6 de Boer IH, Rue TC, Hall YN. Temporal trends in the prevalence of diabetic kidney disease in the United States. JAMA 2011;305:2532-9.

7 Gregg EW, Li Y, Wang J, et al. Changes in diabetes-related complications in the United States, 1990-2010. N Engl J Med 2014;370:1514-23.

8 Shaw JE, Sicree RA, Zimmet PZ. Global estimates of the prevalence of diabetes for 2010 and 2030. Diabetes Res Clin Pract 2010;87:4-14.

9 Thomas MC, Cooper ME, Zimmet P. Changing epidemiology of type 2 diabetes mellitus and associated chronic kidney disease. Nat Rev Nephrol 2016;12:73-81.

10 Kidney Disease: Improving Global Outcomes (KDIGO) Diabetes Work Group. KDIGO 2020 clinical practice guideline for diabetes management in chronic kidney disease. Kidney Int 2020;98:S1-115.

11 American Diabetes Association. 11. microvascular complications and foot care: standards of medical care in Diabetes-2021. Diabetes Care 2021;44:S151-67.

12 Coca. Role of intensive glucose control in development of renal end points in type 2 diabetes mellitus: systematic review and metaanalysis. Arch Intern Med 2012;172:1095.

13 Jain N, Reilly RF. Effects of dietary interventions on incidence and progression of CKD. Nat Rev Nephrol 2014;10:712-24.

14 Ko GJ, Obi Y, Tortorici AR, et al. Dietary protein intake and chronic kidney disease. Curr Opin Clin Nutr Metab Care 2017;20:77-85.

15 Nathan DM, Kuenen J, Borg R, et al. Translating the A1c assay into estimated average glucose values. Diabetes Care 2008;31:1473-8.

16 Papachristoforou E, Lambadiari V, Maratou E, et al. Association of glycemic indices (hyperglycemia, glucose variability, and hypoglycemia) with oxidative stress and diabetic complications. J Diabetes Res 2020;2020:1-17.

17 Zelnick LR, Batacchi ZO, Ahmad I, et al. Continuous glucose monitoring and use of alternative markers to assess glycemia in chronic kidney disease. Diabetes Care 2020;43:2379-87.

18 Nathan DM, Cleary PA, Backlund J-YC, et al. Intensive diabetes treatment and cardiovascular disease in patients with type 1 diabetes. N Engl J Med 2005;353:2643-53.

19 DCCT/EDIC Research Group, de Boer IH, Sun W, et al. Intensive diabetes therapy and glomerular filtration rate in type 1 diabetes. $N$ Engl J Med 2011;365:2366-76.

20 Bilous R. Microvascular disease: what does the UKPDS tell us about diabetic nephropathy? Diabet Med 2008;25:25-9.

21 Wong MG, Perkovic V, Chalmers J, et al. Long-term benefits of intensive glucose control for preventing end-stage kidney disease: ADVANCE-ON. Diabetes Care 2016;39:694-700.

22 Oellgaard J, Gæde P, Rossing P, et al. Intensified multifactorial intervention in type 2 diabetics with microalbuminuria leads to longterm renal benefits. Kidney Int 2017;91:982-8.

23 Action to Control Cardiovascular Risk in Diabetes Study Group, Gerstein HC, Miller ME, et al. Effects of intensive glucose lowering in type 2 diabetes. N Engl J Med 2008;358:2545-59.

24 Holman RR, Paul SK, Bethel MA, et al. 10-Year follow-up of intensive glucose control in type 2 diabetes. N Engl J Med 2008;359:1577-89.

25 Schernthaner G, Schernthaner-Reiter MH. Therapy: risk of metformin use in patients with T2DM and advanced CKD. Nat Rev Endocrinol 2015;11:697-9.

26 Kwon S, Kim YC, Park JY, et al. The long-term effects of metformin on patients with type 2 diabetic kidney disease. Diabetes Care 2020;43:948-55.

27 Roumie CL, Chipman J, Min JY, et al. Association of treatment with metformin vs sulfonylurea with major adverse cardiovascular events among patients with diabetes and reduced kidney function. JAMA 2019;322:1167-77.

28 Roussel R, Travert F, Pasquet B, et al. Metformin use and mortality among patients with diabetes and atherothrombosis. Arch Intern Med 2010;170:1892-9.

29 Lazarus B, Wu A, Shin J-I, et al. Association of metformin use with risk of lactic acidosis across the range of kidney function. JAMA Intern Med 2018;178:903-10.
30 Chu PY, Hackstadt AJ, Chipman J, et al. Hospitalization for lactic acidosis among patients with reduced kidney function treated with metformin or sulfonylureas. Diabetes Care 2020;43:1462-70.

31 Ekström N, Schiöler L, Svensson A-M, et al. Effectiveness and safety of metformin in 51675 patients with type 2 diabetes and different levels of renal function: a cohort study from the Swedish national diabetes register. BMJ Open 2012;2:e001076.

32 Petrykiv S, Sjöström CD, Greasley PJ, et al. Differential effects of dapagliflozin on cardiovascular risk factors at varying degrees of renal function. Clin J Am Soc Nephrol 2017;12:751-9.

33 Wanner C, Inzucchi SE, Lachin JM, et al. Empagliflozin and progression of kidney disease in type 2 diabetes. $N$ Engl J Med 2016;375:323-34.

34 Wanner C, Inzucchi SE, Zinman B, et al. Consistent effects of empagliflozin on cardiovascular and kidney outcomes irrespective of diabetic kidney disease categories: insights from the EMPA-REG outcome trial. Diabetes Obes Metab 2020;22:2335-47.

35 Neal B, Perkovic V, Mahaffey KW, et al. Canagliflozin and cardiovascular and renal events in type 2 diabetes. N Engl J Med 2017:377:644-57.

36 Wiviott SD, Raz I, Bonaca MP, et al. Dapagliflozin and cardiovascular outcomes in type 2 diabetes. N Engl J Med 2019;380:347-57.

37 Perkovic V, Jardine MJ, Neal B, et al. Canagliflozin and renal outcomes in type 2 diabetes and nephropathy. $N$ Engl $J$ Med 2019;380:2295-306

38 Herrington WG, Preiss D, Haynes R, et al. The potential for improving cardio-renal outcomes by sodium-glucose co-transporter-2 inhibition in people with chronic kidney disease: a rationale for the EMPA-KIDNEY study. Clin Kidney J 2018;11:749-61.

39 Musso G, Gambino R, Cassader M, et al. Efficacy and safety of dual SGLT 1/2 inhibitor sotagliflozin in type 1 diabetes: meta-analysis of randomised controlled trials. BMJ 2019;60:I1328.

40 Powell DR, Zambrowicz B, Morrow L, et al. Sotagliflozin decreases postprandial glucose and insulin concentrations by delaying intestinal glucose absorption. J Clin Endocrinol Metab 2020;105:e1235-49.

41 Bhatt DL, Szarek M, Pitt B, et al. Sotagliflozin in patients with diabetes and chronic kidney disease. $N$ Engl J Med 2021;384:129-39.

42 Bhatt DL, Szarek M, Steg PG, et al. Sotagliflozin in patients with diabetes and recent worsening heart failure. N Engl J Med 2021;384:117-28.

43 Liu J, Li L, Li S, et al. Effects of SGLT2 inhibitors on UTIs and genital infections in type 2 diabetes mellitus: a systematic review and metaanalysis. Sci Rep 2017;7.

44 Bersoff-Matcha SJ, Chamberlain C, Cao C, et al. Fournier gangrene associated with sodium-glucose cotransporter-2 inhibitors: a review of spontaneous postmarketing cases. Ann Intern Med 2019;170:764-9.

45 Ferrannini E, Baldi S, Frascerra S, et al. Shift to fatty substrate utilization in response to sodium-glucose cotransporter 2 inhibition in subjects without diabetes and patients with type 2 diabetes. Diabetes 2016;65:1190-5.

46 Palmer BF, Clegg DJ. Euglycemic ketoacidosis as a complication of SGLT2 inhibitor therapy. Clin J Am Soc Nephrol 2021;17621120. doi:10.2215/CJN.17621120. [Epub ahead of print: 09 Feb 2021].

47 Fralick M, Schneeweiss S, Patorno E. Risk of diabetic ketoacidosis after initiation of an SGLT2 inhibitor. N Engl J Med 2017;376:2300-2

48 Menne J, Dumann E, Haller H, et al. Acute kidney injury and adverse renal events in patients receiving SGLT2-inhibitors: a systematic review and meta-analysis. PLoS Med 2019;16:e1002983.

49 Heise T, Jordan J, Wanner C, et al. Pharmacodynamic effects of single and multiple doses of Empagliflozin in patients with type 2 diabetes. Clin Ther 2016;38:2265-76.

50 Tanaka T, Higashijima Y, Wada T, et al. The potential for renoprotection with incretin-based drugs. Kidney Int 2014;86:701-11.

51 Mann JFE, Ørsted DD, Brown-Frandsen K, et al. Liraglutide and renal outcomes in type 2 diabetes. N Engl J Med 2017;377:839-48.

52 Marso SP, Bain SC, Consoli A, et al. Semaglutide and cardiovascular outcomes in patients with type 2 diabetes. N Engl J Med 2016;375:1834-44.

53 Husain M, Birkenfeld AL, Donsmark M, et al. Oral Semaglutide and cardiovascular outcomes in patients with type 2 diabetes. $N$ Engl J Med 2019;381:841-51.

54 Tuttle KR, Lakshmanan MC, Rayner B, et al. Dulaglutide versus insulin Glargine in patients with type 2 diabetes and moderate-tosevere chronic kidney disease (AWARD-7): a multicentre, open-label, randomised trial. Lancet Diabetes Endocrinol 2018;6:605-17. 
55 Gerstein HC, Colhoun HM, Dagenais GR, et al. Dulaglutide and cardiovascular outcomes in type 2 diabetes (REWIND): a double-blind, randomised placebo-controlled trial. The Lancet 2019;394:121-30.

56 Zelniker TA, Wiviott SD, Raz I, et al. Comparison of the effects of glucagon-like peptide receptor agonists and sodium-glucose cotransporter 2 inhibitors for prevention of major adverse cardiovascular and renal outcomes in type 2 diabetes mellitus. Circulation 2019;139:2022-31.

57 Packer M, Anker SD, Butler J, et al. Effect of Empagliflozin on the clinical stability of patients with heart failure and a reduced ejection fraction. Circulation 2021;143:326-36.

58 Margulies KB, Hernandez AF, Redfield MM, et al. Effects of liraglutide on clinical stability among patients with advanced heart failure and reduced ejection fraction. JAMA 2016;316:500-8.

59 Jabbour SA, Frías JP, Ahmed A, et al. Efficacy and safety over 2 years of exenatide plus dapagliflozin in the DURATION-8 study: a multicenter, double-blind, phase 3 , randomized controlled trial. Diabetes Care 2020;43:2528-36.
60 Snyder RW, Berns JS. Use of insulin and oral hypoglycemic medications in patients with diabetes mellitus and advanced kidney disease. Semin Dial 2004;17:365-70.

61 Zhang Y, He D, Zhang W, et al. Ace inhibitor benefit to kidney and cardiovascular outcomes for patients with non-dialysis chronic kidney disease stages 3-5: a network meta-analysis of randomised clinical trials. Drugs 2020;80:797-811.

62 Currie G, Taylor AHM, Fujita T, et al. Effect of mineralocorticoid receptor antagonists on proteinuria and progression of chronic kidney disease: a systematic review and meta-analysis. BMC Nephrol 2016;17.

63 Agarwal R, Kolkhof P, Bakris G, et al. Steroidal and non-steroidal mineralocorticoid receptor antagonists in cardiorenal medicine. Eur Heart J 2021;42:152-61.

64 Bakris GL, Agarwal R, Chan JC, et al. Effect of finerenone on albuminuria in patients with diabetic nephropathy: a randomized clinical trial. JAMA 2015;314:884-94.

65 Bakris GL, Agarwal R, Anker SD, et al. Effect of finerenone on chronic kidney disease outcomes in type 2 diabetes. N Engl J Med 2020;383:2219-29. 